\title{
Contents of the Next Issue of Opticheskii Zhurnal (Journal of Optical Technology)
}

DOI: $10.1134 / \mathrm{S} 0030400 \mathrm{X} 11120241$

The following papers on the topic Laser Physics and Technology will be published in the October special issue of Opticheskii Zhurnal (Journal of Optical Technology), Vol. 78, No. 10, 2011.

Preface by the issue's editor (L.N. Soms).

A Mode-Locked CO Laser for Uranium Isotope Separation in a Free Jet (I.Ya. Baranov and A.V. Koptev);

A Transmitting Laser Module with the Switchable Directivity Diagram for the Space Vessel FOBOSGRUNT (V.M. Plolyakov, V.P. Pokrovskii, and L.N. Soms);

A Piezocorrector for Compensation of Thermal Variations in the Optical Cavity Path Length of a Laser Gyroscope (N.P. Zapotyl'ko, A.A. Katkov, and A.A. Nedzvetskaya);

A Piezo Actuator for a Ring Laser Gyroscope (N.P. Zapotyl'ko, A.A. Nedzvetskaya, and I.N. Polekhin);

An Algorithm for Signal Processing of an Interference Angular Null Indicator for Calibration of Prisms with Faces without Reflective Coating (Yu.V. Filatov and M.S. Nikolaev);

The Pulse Length in a Spatial Chirp of a Two-Grating Delay Line (A.V. Gitin and A.A. Andreev);

Lead Borate Oxyfluoride Glasses Doped with $\mathrm{Nd}^{3+}$ Ions and Transparent Glass Ceramic Materials on
Their Basis (O.B. Petrova, A.V. Popov, V.E. Shukshin, and Yu.K. Voron'ko);

Quantitative Determination of the Calcium Ion Content from Fluorescence Measurements of SingleLong-Wavelength Dyes Using Laser Scanning Microscopy (Yu.N. Zakharov and A.V. Ershova);

Thermal Imaging Monitoring of the Microcirculation Blood Heating Processes during Low-Intensity Laser Therapeutic Procedures (D.A. Rogatkin, K.S. Litvinova, D.S. Makarov, O.A. Bychenkov, and M.I. Shcherbakov);

Optimization of the Transfer Characteristics of Erbium Fiber Amplifiers by a Genetic Algorithm (M.A. Khodasevich, G.V. Sinitsyn, and Yu.A. Varaksa);

The Effect of the Light Bleaching on Watercolors in Restoration of Graphic Artworks (S.A. Dobrusina, N.S. Volgushkina, and N.G. Gerasimova);

The Effect of the Nonlinear Numerical Speckle Pattern Processing on the Accuracy of the Displacement Determination in Speckle Photography (A.A. Grebenyuk and V.P. Ryabukho);

A Setup for Determination of the Spatial Characteristics of Laser Radiation (A.V. Isaevich and A.V. Kholenkov).

Compiled by L.V. Enushevskaya

Translated by S. Belov 